\title{
Bazı Arpa Çeşitlerinin (Hordeum vulgare L.) Çimlenme Dönemlerinde Farklı Dozlardaki Tuz Stresine Tepkilerinin Belirlenmesi
}

\author{
*Berk BENLIOĞLU
}

Uğur ÖZKAN

Ankara Üniversitesi, Ziraat Fakültesi, Tarla Bitkileri Bölümü, Dışkapı/ANKARA

*Sorumlu yazar e-posta (Corresponding author; e-mail): benliogluberk@hotmail.com

Geliş Tarihi (Received): 01.10.2015 Kabul Tarihi (Accepted): 14.12.2015

Öz

Bu araştırma Ankara Üniversitesi Ziraat Fakültesi Tarla Bitkileri Bölümü laboratuvarında, bazı arpa çeşitlerinin çimlenme aşamasında tuz stresine olan tepkilerinin belirlenmesi amacıyla yürütülmüştür. Çalışmada bitki materyali olarak Türkiye'de arpa yetiştiriciliği açısında büyük önem taşıyan; Aydanhanım, Bülbül-89 ve Tarm-92 iki sıralı arpa çeşitleri kullanılmıştır. Tuz stresi için NaCl'nin 5 dozu (3, 6, 9, 12 ve 15 $\mathrm{g} / \mathrm{l})$ ve kontrol grubu olarak da saf su $(0 \mathrm{~g} / \mathrm{l})$ uygulanmıştır. Çalışmanın 4 . gününde çimlenmiş olan tohumlar sayılarak "Çimlenme Hızı" ve 8. günde ikinci sayım ve diğer ölçümler yapılarak "çimlenme gücü", "kök uzunluğu", "sürgün uzunluğu”, "yaş ve kuru ağırlık" parametreleri belirlenmiştir. Alınan sonuçlara göre çeşitler, "çimlenme gücü”, "kök uzunluğu”, "sürgün uzunluğu” ve "kuru ağırlık” parametreleri istatistiki anlamda önemli bulunmuştur. Bununla birlikte; tuz dozları için incelenen tüm parametreler ve çeşit $x$ tuz interaksiyonları için ise; "kök uzunluğu", "yaş ve kuru ağırık" parametrelerinin de istatistiksel olarak önemli çıktığı belirlenmiştir. İncelenen tüm parametrelerde Tarm-92 çeşidinin diğer çeşitlere göre tuza toleransının daha yüksek olduğu tespit edilmiştir.

Anahtar Kelimeler: Arpa, Hordeum vulgare L., çimlenme, tuz stresi, $\mathrm{NaCl}$

\section{Determination of Responses of some Barley Cultivars (Hordeum vulgare L.) to Salt Stress in Different Doses at the Germination Period}

\begin{abstract}
This research was carried out to determine responses of some barley cultivars to salt stress at germination period in laboratory conditions. In this study, Aydanhanım, Bülbül-89 and Tarm-92, which are double-row barley cultivars and have a great importance in terms of barley cultivation in Turkey, were used as a plant material. Six different $\mathrm{NaCl}$ doses $(0,3,6,9,12$ and $15 \mathrm{~g} / \mathrm{l})$ were applied. Germination speed on $4^{\text {th }}$ day of the study, "germination power", "root length", "shoot length", "fresh and dry weight" on $8^{\text {th }}$ day of the study were examined. According to results; "germination speed", "root length", "shoot length" and "dry matter" has a significant interaction for cultivar interaction. In addition to; all parameters has a significant interaction for $\mathrm{NaCl}$ doses and cultivar x $\mathrm{NaCl}$ doses interaction's; "root length", "fresh weight" and "dry matter" has a significant interaction too. It has been found that Tarm-92 cultivar was higher salt tolerance than other cultivar.
\end{abstract}

Keywords: Barley, Hordeum vulgare L., germination, salt stress, $\mathrm{NaCl}$

\section{Giriş}

A rpa, Dünya'da tahıllar içerisinde buğday, mısır ve çeltikten sonra en fazla yetiştirilen cinstir. Arpa önemli bir hayvan yemi olup, besleyicilik değeri mısırın \%95'i kadardır. Aynı zamanda arpa bira sanayisinin de temel hammaddesidir.

Artan nüfusun ihtiyaçlarının karşılanması, hatalı tarımsal faaliyetler ve erozyon sonucu verimliliğin azalması, tarım alanlarının amaç dışı kullanılması ve stres faktörlerinin giderek şiddetlenmesi gibi nedenlerle daralan ekim alanlarından birim alan veriminin artması zorunlu hale gelmiştir. Bunun içinde; yüksek verimli, yüksek kaliteli ve stres faktörlerine dayanıklı çeşitler geliştirmek önemlidir. Ayrıca bölgelerin iklim ve toprak faktörlerine uygun bitki ve çeşitlerin yetiştirilmesi de büyük önem taşımaktadır.

Bitkilerde stres tarımsal üretimi sınırlayan en önemli nedenlerin başında yer almaktadır. Bitkilerde stres; büyüme ve gelişmeyi olumsuz etkileyen dış etkenler olarak tanımlanmaktadır. Bu etkenler, biyotik (bitkiler, mikroorganizmalar 
vs) ve abiyotik (kuraklık, mineral maddeler, ekstrem sıcaklıklar vs) stres faktörleri olmak üzere iki başlık altında toplanırlar (Larcher 1995).

Tuzluluk, kuraklıktan sonra tarımsal üretimi en fazla sınırlayan abiyotik stres faktörüdür. Bugün dünyada bitkisel üretim yapılan alanların yaklaşık \%15-20'si ve sulu tarım alanlarının ise yaklaşık \%20-50'si tuzluluktan etkilenmektedir (Zhu 2001; Pitman and Läuchli 2002; Tuteja 2007). Ülkemizde ise verimsiz alanlar yüzey alanının \%2'sini kaplarken, bu çorak alanların da \%74'ü tuzlu topraklardan oluşturmaktadır (Kendirli ve ark. 2005). Bitkilerde osmotik stres ve iyon stresi şeklinde ortaya çıkan tuzluluk stresi, büyüme ve gelişimi engelleyerek bitkide; yapısal, fizyolojik, biyokimyasal ve moleküler düzeylerde değişimlere yol açmaktadır (Çulha ve Çakırlar 2011).

Arpa, tuzluluğa toleransı en yüksek bitkilerden biridir. Tuz stresi birçok bitkide olduğu gibi arpada da bütün büyüme ve gelişme dönemlerinde etkilemekle birlikte en fazla çimlenme ve çıkış aşamasında etkilemektedir (Begum et al. 1992; Parlak 1999). Birçok bitkinin yaşamına devam edemeyeceği $\quad \mathrm{Ec}_{\mathrm{e}}=8 \mathrm{dS} / \mathrm{m}$ tuzluluk düzeyi arpanın verimini düşürmeye başladığı eşik değerdir. Sırasıyla $\mathrm{EC}_{\mathrm{e}}=10,13$ ve $18 \mathrm{dS} / \mathrm{m}$ tuz yoğunlukları, arpa bitkisi için \%10, 25 ve 50 verim kaybına sebebiyet vermektedir (Ekmekçi 2005).

Tuzluluk probleminin görüldüğü alanlarda yapılan tarımsal faaliyetlerin tatmin edici verim sağlaması için mevcut ve yeni ıslah edilmiş çeşitlerin tuzluluğa olan toleranslarının belirlenmesi çok önemlidir. Çalışmamızda Türkiye'de arpa yetiştiriciliği açısından önem taşıyan, Aydanhanım, Bülbül-89 ve Tarm-92 iki sıralı arpa çeşitlerinin çimlenme döneminde farklı konsantrasyonlardaki tuz stresine olan tepkileri belirlenmeye çalışılmıştır.

\section{Materyal ve Yöntem}

Çalışma 2014-2015 sezonunda Ankara Üniversitesi Ziraat Fakültesi Tarla Bitkileri Bölümü Laboratuvarı'nda yürütülmüştür. Araştırmamızda deney materyali olarak kullanılan Aydanhanım, Bülbül-89 ve Tarm-92 iki sıralı arpa çeşitlerine ait tohumlar Tarla Bitkileri Merkez Araştırma Enstitüsü Müdürlüğü Arpa Islah Bölümünden temin edilmiştir.

Tuz formu olarak toprakta en çok bulunan, toprak bünyesinde biriken ve kültür bitkilerini en fazla etkileyen $\mathrm{NaCl}$ formu kullanılmıştır (Munns ve Termaat 1986). Kontrol olarak 0 dozunun değerlendirildiği çalışmada arpa bitkisinin verimini $\% 50$ kaybettiği tuzluluk değeri olan 18
$\mathrm{dS} / \mathrm{m}$ derecesine kadar olan (Ekmekçi vd. 2005); 3, 6, 9, 12, $15 \mathrm{~g} / \mathrm{l}(4.68,7.14,10.71,14.29,17.86$ $\left.\mathrm{EC}_{\mathrm{e}}, \mathrm{dS} / \mathrm{m}\right) 6 \mathrm{NaCl}$ dozunda incelemeler yapılmıştır. Tohumlar $24 \pm 1{ }^{\circ} \mathrm{C}$ 'de karanlık şartlarda çimlenmeye bırakılmıştır. Parametreler ISTA kurallarına uygun olarak 4. ve 8. günlerde yapılan ölçüm ve sayımlarla elde edilmiştir. 4 . günde çimlenen tohumlar sayılarak "çimlenme hızı", 8. günde yapılan sayım ve ölçümler ile de "çimlenme gücü", "kök uzunluğu", "sürgün uzunluğu", "yaş ağırlık" ve "kuru ağırlık" parametreleri her petriden tesadüf olarak seçilen 10'ar adet tohumun ölçülüp ortalamasını alınmasıyla belirlenmiştir. Kuru ağırlığın ölçülmesi için yaş sürgünler $105^{\circ} \mathrm{C}$ 'de 2 saat kurutulmuştur (Yıldız and Özgen 2004).

Tohumların yüzey sterilizasyonlarının sağlanması amacıyla, $15 \mathrm{dk}$ süreyle, \%5'lik sodyum hipoklorit çözeltisi içerisinde $(\mathrm{NaClO})$ çalkalanıp, sodyum hipokloritin uzaklaştırılması amacıyla birkaç kere saf su ile durulanmıştır. Önceden steril edilmiş ve içerilerine steril filtre kağıtları olan petrilere, yüzey sterilizasyonu sağlanan tohumlar yerleştirilip üzerine filtre kağıdı ve gerekli tuz dozundan $5 \mathrm{ml}$ konularak etrafı streç film ile sarılarak iklim odasına kaldırılmıştır(Koyuncu 2008).

Denemeler Tesadüf parselleri deneme desenine göre 3 tekrarlamalı olarak kurulmuştur. Her uygulama için petri kutularına 15'er adet arpa tohumları konulmuştur. Elde edilen verilerin istatistiksel analizi SPSS 20 istatistik paket programıyla yapılmıştır (IBM Corp, 2011).

\section{Bulgular ve Tartışma}

Çalışmada kullanılan arpa çeşitlerinden elde edilen "Çimlenme Hızı”, “Çimlenme Gücü”, “Kök Uzunluğu”, "Sürgün Uzunluğu”, "Yaş Ağırlık” ve "Kuru Ağırlık" parametrelerine ilişkin varyans analiz tablosu Çizelge 1'de verilmiştir.

Çizelge 1.'den de görüldüğü gibi incelenen tüm parametreler üzerinde tuz dozları istatistiki olarak \% 1 düzeyinde önemli, çeşit; "Çimlenme Hızı" ve "Yaş Ağırıı" üzerinde istatistiki olarak önemsiz, "Çimlenme Gücü" ve "Sürgün Uzunluğu" parametrelerinde $\% 5$ düzeyinde önemli ve "Kök Uzunluğu" ve "Kuru Ağırlık" incelendiğinde ise \%1 düzeyinde önemlilik göstermiştir. Tuz x Çeşit interaksiyonunda ise; Çimlenme Hızı", "Çimlenme Gücü" ve "Sürgün U̧zunluğu" parametrelerinde önemsiz, "Kök Uzunluğu" ve "Yaş Ağırlık" parametrelerinde \%1 düzeyinde, "Kuru Ağırlık" da \%5 düzeyinde önemli bulunmuştur. İncelenen parametrelerin ortalamaları ve önem grupları Çizelge 2.'de yer almaktadır. 
Çizelge 1. Arpa çeşitlerinin farklı tuz konsantrasyonlarında incelenen parametrelere ilişkin varyans analizi Table 1. Variance analysis of Different $\mathrm{NaCl}$ concentration of Barley's Cultivars

\begin{tabular}{lcccrrrr}
\hline V.K. & S.D. & \multicolumn{7}{c}{ F Değerleri } \\
\hline & & $\begin{array}{c}\text { Çimlenme } \\
\text { Hızı }\end{array}$ & $\begin{array}{c}\text { Çimlenme } \\
\text { Gücü }\end{array}$ & $\begin{array}{c}\text { Kök } \\
\text { Uzunluğu }\end{array}$ & $\begin{array}{c}\text { Sürgün } \\
\text { Uzunluğu }\end{array}$ & Yaş Ağırlık & $\begin{array}{c}\text { Kuru } \\
\text { Ağırlık }\end{array}$ \\
\hline Çeşit & 2 & $4.560 \mathrm{~ns}$ & $7.674^{*}$ & $36.304^{* *}$ & $6.055^{*}$ & $2.817 \mathrm{~ns}$ & $21.523^{* *}$ \\
Tuz & 5 & $12.764^{* *}$ & $5.393^{* *}$ & $167.395^{* *}$ & $170.560^{* *}$ & $186.789^{* *}$ & $12.444^{* *}$ \\
Tuz x Çeşit & 10 & $0.826 \mathrm{~ns}$ & $0.744 \mathrm{~ns}$ & $5.083^{* *}$ & $1.366 \mathrm{~ns}$ & $3.711^{* *}$ & $2.135^{*}$ \\
Hata & 36 & - & - & - & - & - & - \\
Genel & 53 & - & - & - & - & - & -
\end{tabular}

*: 0.05 düzeyinde önemli, **: 0.01 düzeyinde önemli, ns: önemli değil.

${ }^{*},{ }^{* *}$; Significant at the 0.05 and 0.01 probability level, ns: non significant.

\section{Çimlenme Hızı ve Gücü}

Araştırmada ele alınan tüm çeşitlerde tuz dozları arttıkça çimlenme hızının azaldığı görülmektedir. Tuz konsantrasyonlarına bakarak en yüksek ve en düşük dozlar arasında farkın yaklaşık olarak \%21 olduğu görülmektedir. En yüksek çimlenme hızı $0 \mathrm{~g} / \mathrm{l}$ olan kontrol grubunda (\%95.6) olurken, en düşük çimlenme hızı ise $15 \mathrm{~g} / \mathrm{l}$ tuz dozunda (\%75.8) görülmüştür.

Çeşitlerin çimlenme güçleri ele alındığında en yüksek çimlenme oranına Tarm-92 (\%96.3) çeşidinin sahip olduğu ve en düşük orana da Bülbül-89 (\%87.4) çeşidinin sahip olduğu görülmektedir. Artan tuz dozlarının çimlenmeye başlama süresini geciktirdiği 4 . Günden sonra çimlenme oranın arttığı da Tablo 2.'den görülmektedir.

Tuz dozları ele alındığında ise çimlenme hızında olduğu gibi çimlenme gücü parametresinde de en yüksek oran \%97.8 ile kontrol dozunda olurken, en düşük oran ise \%85.9 ile $15 \mathrm{~g} / \mathrm{l}$ tuz dozunda gerçekleşmiştir. Çimlenme oranının ve çimlenme hızının tuz dozları arttıkça azalığı bu bulgularla söylenebilmektedir ve diğer araştırmalarla paralellik göstermektedir (Huang and Redmann 1995; Pancholi et al. 2001; Prazak et al. 2001; Şenay ve ark. 2005; Kara ve ark. 2011).

\section{Kök ve Sürgün Uzunluğu}

Tuz x Çeşit interaksiyonunun istatistiki olarak önemli çıktığı kök uzunluğunda, 6 g/l tuz dozuyla birlikte doz artışında keskin düşüşler meydana gelmiştir. En fazla kök uzunluğu $3 \mathrm{~g} / \mathrm{l}$ tuz dozunda Tarm-92 çeşidinde görülürken $(12.1 \mathrm{~cm})$, en az ise $15 \mathrm{~g} / \mathrm{l} \mathrm{tuz}$ dozunda Bülbül-89 çeşidinde görülmüştür (2.6 $\mathrm{cm}$ ). Düşük tuz dozlarında köklerin daha çok geliştiği görülürken, Tarm-92 çeşidinin kök uzunluğu; kontrol grubu ve $15 \mathrm{~g} / \mathrm{l}$ dozu arasında \%63'lük bir azalma söz konusuyken Aydanhanım çeşidinde $\% 74$ ve Bülbül-89 çeşidinde ise \%82'lik bir azalma olmuştur. Bu değerlere bakarak Tarm-92 çeşidinin tuzlu koşullarda Aydanhanım ve Bülbül-89 çeşitlerine göre daha iyi kök gelişimine sahip olduğu söylenebilmektedir. Kök uzunluğunun tuz stresinden belirgin ölçüde etkilendiğini belirtmişlerdir (Jamil et al. 2005; Dumlupınar ve ark. 2007; Jafarzadeh and Aliasgharzad 2007). Bu bilgiler ışığında tuza toleranslı genotiplerin seçiminde kök uzunluğu yararlanılabilecek önemli bir parametredir (Khan et al. 2003). Yapılan korelasyon analizine göre kök uzunluğu, sürgün uzunluğu $(r=0.911)$ ve yaş ağırlık ( $r=0.905)$ parametreleri ile yüksek oranda görülmüştür (Tablo 3 ).

Arpa çeşitlerinin 6 farklı $\mathrm{NaCl}$ dozundaki sürgün uzunlukları ortalamaları $6.3-7.2 \mathrm{~cm}$ arasında değişmektedir. En yüksek sürgün uzunluğu kontrol grubundan elde edilirken $(9.3 \mathrm{~cm})$ en düşük sürgün uzunluğu ise $15 \mathrm{~g} / \mathrm{l}$ dozundan elde edilmiştir $(2.3 \mathrm{~cm}) .9 \mathrm{~g} / \mathrm{l}$ dozundan itibaren sürgün uzunluklarında hızla düşüşler görülmektedir. Çeşitlerin kontrol grubu ve $15 \mathrm{~g} / \mathrm{l}$ dozu arasındaki farklılıkları incelendiğinde sürgün uzunluğu kaybı \%66 ile en az olan çeşit Tarm-92'dir. Bunu \%81 ile Aydanhanım ve $\% 82$ ile de Bülbül-89 çeşitleri takip etmektedir. Çizelge 2'de de görüldüğü gibi artan tuz dozlarında Tarm-92, Aydanhanım ve Bülbül-89 çeşitlerine göre daha yüksek gelişme göstermiştir. Çeşitlerin ortalama sürgün uzunluklarının $0 \mathrm{~g} / \mathrm{l}$ dozundan $15 \mathrm{~g} / \mathrm{l}$ dozuna çıkmasıyla \%76 oranında azalma meydana gelmiştir. Sadat Noori and Mcneilly (2000); El Madidi et al. (2004); Dumlupınar ve ark. (2007); Patterson et al. (2009); Kara ve 
ark. (2011); tuz dozlarının artmasıyla sürgün uzunluklarının azaldığını belirtmişlerdir ve bu sonuçlar bulgularımızla uyumluluk göstermektedir. Araştırmada incelenen parametreler arasında en yüksek korelasyon, sürgün uzunluğu ile yaş ağırlık arasında meydana gelmiştir $(r=0.928)$ (Tablo 3).

\section{Yaş ve Kuru Ağırlık}

Arpa çeşitlerin yaş ağırlıkları incelendiğinde Bülbül-89 çeşidinin $3 \mathrm{~g} / \mathrm{l}$ tuz dozunda gelişen uygulamasının $3,085 \mathrm{~g}$ ile en yüksek ağırlık değerine eriştiği, $15 \mathrm{~g} / \mathrm{l}$ dozundaki Aydanhanım ve Bülbül 89 çeşitlerinin ise aynı grupta yer alarak en düşük yaş ağırık değerine sahip olmuştur. En yüksek yaş ağırlık ortalamasının elde edildiği $3 \mathrm{~g} / \mathrm{l}$ dozu ile en düşük yaş ağırık ortalamasının elde edildiği $15 \mathrm{~g} / \mathrm{l}$ dozu arasında yaklaşık olarak \%53'lük bir azalma görülmektedir. Tuz konsantrasyonunun artmasıyla birlikte yaş ağırlığın azaldığı sonucumuz diğer araştırmaların sonuçlarıyla desteklenmektedir (Saboraa et al. 2006; Karakullukçu ve Adak 2009). Çizelge 2. İncelendiğinde Tarm-92 çeşidi diğer çeşitlere göre artan tuz dozlarında daha yüksek oranda yaş ağırlık meydana getirmiştir.

Örneklerin kuru ağırlıklara bakıldığında, en çok $15 \mathrm{~g} / \mathrm{l}$ tuz dozunda Bülbül-89 çeşidinde $(0.473 \mathrm{~g})$, en az ise kontrol grubu Aydanhanım çeşidinde $(0.358 \mathrm{~g})$ kuru ağırlık değerleri elde edilmiştir. Tuz konsantrasyonun artmasıyla birlikte kuru ağırlık miktarının arttığı Çizelge 2.'de görülmektedir. Yüksek tuz konsantrasyonu çimlenme süresince tohumların besin maddeleri tüketimini azaltmasıyla çimlenmenin yetersiz kalmasına sebep olmaktadır. (Sultana et al. 2000). Kuru ağırık, tuz dozlarının artmasına paralel olarak arttığı, araştırmamızda incelenen tüm parametrelerle negatif korelasyon göstermiştir (Çizelge 3).

Çizelge 2. Arpa çeşitlerinin farklı $\mathrm{NaCl}$ dozlarındaki ortalama değerleri Table 2. Different $\mathrm{NaCl}$ doses of barley's cultivars means value

\begin{tabular}{|c|c|c|c|c|c|c|c|}
\hline \multirow{2}{*}{ Çeşitler } & \multicolumn{6}{|c|}{ Çimlenme Hızı (\%) } & \multirow{2}{*}{ Ortalama } \\
\hline & 0 & $3 \mathrm{~g} / \mathrm{l}$ & $6 \mathrm{~g} / \mathrm{l}$ & $9 \mathrm{~g} / \mathrm{l}$ & $12 \mathrm{~g} / \mathrm{l}$ & $15 \mathrm{~g} / \mathrm{l}$ & \\
\hline Aydanhanım & 97.8 & 93.3 & 93.3 & 85.5 & 82.2 & 73.3 & $87.6 \mathrm{~b}$ \\
\hline Bülbül-89 & 91.1 & 86.6 & 93.3 & 86.6 & 77.7 & 67.4 & $83.8 \mathrm{bc}$ \\
\hline Tarm-92 & 97.8 & 97.8 & 97.8 & 95.5 & 86.6 & 86.7 & $93.7 \mathrm{a}$ \\
\hline Ortalama & 95.6 a & $92.6 \mathrm{a}$ & $94.8 \mathrm{a}$ & $89.2 \mathrm{ab}$ & $82.2 \mathrm{bc}$ & $75.8 \mathrm{c}$ & \\
\hline \multicolumn{8}{|c|}{ Çimlenme Gücü (\%) } \\
\hline Aydanhanım & 100 & 95.5 & 95.5 & 95.5 & 86.7 & 91.1 & $94.1 \mathrm{a}$ \\
\hline Bülbül-89 & 95.5 & 86.6 & 93.3 & 88.9 & 88.0 & 77.8 & $87.4 \mathrm{~b}$ \\
\hline Tarm-92 & 97.8 & 97.8 & 97.8 & 97.8 & 91.1 & 95.5 & $96.3 \mathrm{a}$ \\
\hline Ortalama & $97.8 \mathrm{a}$ & $93.3 \mathrm{ab}$ & $95.5 \mathrm{a}$ & $94.1 \mathrm{ab}$ & $88.6 \mathrm{bc}$ & $85.9 \mathrm{c}$ & \\
\hline \multicolumn{8}{|c|}{ Kök Uzunluğu (cm) } \\
\hline Aydanhanım & $10.3 \mathrm{bc}$ & $9.9 \mathrm{~cd}$ & 8.3 ef & $7.1 \mathrm{f}$ & $3.7 \mathrm{hi}$ & $2.7 \mathrm{i}$ & $7.0 \mathrm{f}$ \\
\hline Bülbül-89 & $8.8 \mathrm{de}$ & $8.8 \mathrm{de}$ & $5.7 \mathrm{~g}$ & $5.6 \mathrm{~g}$ & $3.9 \mathrm{~h}$ & $2.6 \mathrm{i}$ & $5.9 \mathrm{~g}$ \\
\hline Tarm-92 & $10.7 \mathrm{bc}$ & $12.1 \mathrm{a}$ & $11.4 a b$ & $7.1 \mathrm{f}$ & $5.3 \mathrm{~g}$ & $3.9 \mathrm{~h}$ & 8.4 ef \\
\hline Ortalama & $9.9 \mathrm{~cd}$ & $10.3 \mathrm{bc}$ & $8.5 \mathrm{e}$ & $6.6 \mathrm{gf}$ & $4.3 \mathrm{~h}$ & $3.1 \mathrm{hi}$ & \\
\hline \multicolumn{8}{|c|}{ Sürgün Uzunluğu (cm) } \\
\hline Aydanhanım & 10.2 & 9.1 & 7.5 & 6.6 & 3.5 & 1.9 & $6.5 \mathrm{~b}$ \\
\hline Bülbül-89 & 8.7 & 9.1 & 7.2 & 7.2 & 4 & 1.6 & $6.3 \mathrm{~b}$ \\
\hline Tarm-92 & 10.2 & 9.7 & 7.8 & 7.5 & 4.7 & 3.5 & $7.2 \mathrm{a}$ \\
\hline Ortalama & $9.7 \mathrm{a}$ & $9.3 \mathrm{a}$ & $7.5 \mathrm{~b}$ & $7.1 \mathrm{~b}$ & $4.1 \mathrm{c}$ & $2.3 d$ & \\
\hline \multicolumn{8}{|c|}{ Yaş Ağırlık (g) } \\
\hline Aydanhanım & $3.019 a b$ & $2.820 \mathrm{bc}$ & $2.398 \mathrm{~d}$ & $2.211 \mathrm{de}$ & $1.471 \mathrm{gh}$ & $1.312 \mathrm{~h}$ & $2.205 \mathrm{de}$ \\
\hline Bülbül-89 & $2.987 \mathrm{ab}$ & $3.085 \mathrm{a}$ & $2.323 \mathrm{de}$ & $1.882 \mathrm{f}$ & $1.676 \mathrm{fg}$ & $1.321 \mathrm{~h}$ & $2.212 \mathrm{de}$ \\
\hline Tarm-92 & $2.701 \mathrm{c}$ & $2.977 \mathrm{ab}$ & $2.678 \mathrm{c}$ & $2.112 \mathrm{e}$ & $1.537 \mathrm{gh}$ & $1.523 \mathrm{gh}$ & $2.255 \mathrm{e}$ \\
\hline Ortalama & $2.902 \mathrm{~b}$ & $2.961 \mathrm{ab}$ & $2.466 \mathrm{~cd}$ & $2.068 \mathrm{e}$ & $1.561 \mathrm{gh}$ & $1.385 \mathrm{~h}$ & \\
\hline \multicolumn{8}{|c|}{ Kuru Ağırlık (g) } \\
\hline Aydanhanım & $0.358 \mathrm{f}$ & 0.365 ef & 0.366 ef & $0.412 \mathrm{~cd}$ & 0.384 def & 0.403 cde & $0.378 \mathrm{def}$ \\
\hline Bülbül-89 & 0.374 def & $0.409 \mathrm{~cd}$ & $0.410 \mathrm{~cd}$ & $0.436 \mathrm{abc}$ & $0.459 a b$ & $0.473 a$ & $0.427 \mathrm{bc}$ \\
\hline Tarm-92 & 0.384 def & 0.372 def & 0.365 ef & 0.388 def & 0.374 def & $0.433 \mathrm{bc}$ & 0.386 def \\
\hline Ortalama & 0.372 def & 0.382 def & 0.380 def & $0.412 \mathrm{~cd}$ & $0.406 \mathrm{~cd}$ & $0.436 \mathrm{abc}$ & \\
\hline
\end{tabular}

*; Aynı harf grubuna giren ortalamalar arasında Duncan testine göre $\% 5$ seviyesinde önemli farklııklar yoktur.

*; There is no significant difference between the groups with the same letters at $5 \%$ level, respectively. 
Çizelge 3. Karakterler arası korelasyon katsayısı

Table 3. Correlation coefficient between characters

\begin{tabular}{lcccccc}
\hline \multicolumn{1}{c}{ Karakterler } & \multicolumn{6}{c}{ Karakterler Arası Korelasyon Katsayısı } \\
\cline { 2 - 7 } & 1 & 2 & 3 & 4 & 5 & 6 \\
\hline (1) Çimlenme Hızı (\%) & - & $0.825^{* *}$ & $0.718^{* *}$ & $0.711^{* *}$ & $0.612^{* *}$ & $-0.559^{* *}$ \\
(2) Çimlenme Gücü (\%) & - & - & $0.588^{* *}$ & $0.555^{* *}$ & $0.462^{* *}$ & $-0.550^{* *}$ \\
(3) Kök Uzunluğu (cm) & - & - & - & $0.911^{* *}$ & $0.905^{* *}$ & $-0.595^{* *}$ \\
(4) Sürgün Uzunluğu (cm) & - & - & - & - & $0.928^{* *}$ & $-0.541^{* *}$ \\
(5) Yaş Ağırlık (g) & - & - & - & - & - & $-0.482^{* *}$ \\
(6) Kuru Ağırlık (g) & - & - & - & - & - & -
\end{tabular}

**; 0,01 düzeyinde önemli.

** ; Significant at the 0.01 probability level.

\section{Sonuç}

Türkiye'de arpa tarımı açısından önemli olan 3 çeşidin çimlenme döneminde farklı tuz stresine karşı olan tepkilerinin araştırıldığı çalışmamızda tuz dozlarının artmasıyla birlikte incelenen tüm parametrelerde olumsuz yönde değişiklikler meydana gelmiştir. Tuz yoğunluğunun artmasılyla birlikte çimlenme oranının düştüğü ve çimlenmenin geciktiği görülmüştür. Genotiplerin tuzluluğa olan toleranslarının belirlenmesinde önemli parametreler olan kök ve sürgün uzunluğu da tuz yoğunluğunun artmasıyla birlikte azalmıştır. Yaş ağırlık artan tuz dozlarında azalmasına karşılık kuru ağırlık, tuz stresi nedeniyle tohumdaki besin maddelerinin kullanılamaması sebebiyle artmıştır. Ele alınan tüm parametrelerde Tarm-92 çeşidinin tuz stresine Aydanhanım ve Bülbül-89 çeşitlerinden daha toleranslı olduğu yorumu yapılabilmektedir.

\section{Kaynaklar}

Begum F., Karmoker J.L., Fattah Q.A. and Maniruzzaman A.F.M., 1992. The effect of salinity and Its correlation with $\mathrm{K}+. \mathrm{Na}+\mathrm{Cl}-$ accumulation in germinating seeds of Triticum aestivum L. cv. Akbar. Plant Cell Physiology 33(7):1009-1114

Çulha Ş. ve Çakırlar H., 2011. Tuzluluğun Bitkiler Üzerine Etkileri ve Tuz Tolerans Mekanizmaları. Afyon Kocatepe Üniversitesi Fen ve Mühendislik Bilimleri Dergisi, 11(2): $11-34$

Dumlupınar Z., Kara R., Dokuyucu T. ve Akkaya A., 2007. Güneydoğu Anadolu Bölgesinde Yetiştirilen Bazı Makarnalık Buğday Genotiplerinin Çimlenme ve Fide Karakterlerine Elektrik Akımı ve Tuz Konsantrasyonlarının Etkileri. Kahramanmaraş Sütçü İmam Üniversitesi Fen Bilimleri Dergisi. 10(2):100-110
Ekmekçi E., Apan M., ve Kara, T. 2005. Tuzluluğun bitki gelişimine etkisi. Ondokuz Mayıs Üniversitesi Ziraat Fakültesi Dergisi, 20(3), 118-125

El Madidi S.A.I.D., El Baroudi I. and Aameur F.B., 2004. Effects of salinity on germination and early growth of barley (Hordeum vulgare L.) cultivars. Journal of Agricultural Biology, 6: 767-770

Huang J. and Redmann R. E., 1995. Salt tolerance of Hordeum and Brassica species during germination and early seedling growth. Canadian Journal of Plant Science. 75(4). 815-819

IBM Corp. Released 2011. IBM SPSS Statistics for Windows, Version 20.0. Armonk, NY: IBM Corporation

Jafarzadeh A. and Aliasgharzad N., 2007. Salinity and salt composition effects on seed germination and root length of four sugar beet cultivars. Biologia. 62(5):562-564

Jamil M., Lee C.C., Rehman S.U., Lee D.B., Ashraf M. and Rha E.S., 2005. Salinity $(\mathrm{NaCl})$ tolerance of Brassica species at germination and early seedling growth. Electronic Journal of Environmental. Agricultural and Food Chemistry. 4: 970-976

Kara B., Akgün İ. ve Altındal D., 2011. Tritikale Genotiplerinde Çimlenme ve Fide Gelişimi Üzerine Tuzluluğun $(\mathrm{NaCl})$ Etkisi. Selcuk Tarim ve Gida Bilimleri Dergisi. 25(1): 1-9

Karakullukçu E. ve Adak M. S., 2008. Bazı nohut (Cicer arietinum L.) çeşitlerinin tuza toleranslarının belirlenmesi. Tarım Bilimleri Dergisi, 14(4): 313-319

Kendirli B., Çakmak B. and Uçar Y., 2005. Salinity in the Southeastern Anatolia Project (GAP). Turkey: Issues and Options. İrigation and Drainage. 54(1): 115-122 
Khan A.A., Rao S.A. and McNeilly T., 2003 Assessment of salinity tolerance based upon seedling root growth response functions in maize (Zea mays L.). Euphytica. 131(1): 8189

Koyuncu N. 2008. Türkiye'de Yetiştirilen Ekmeklik ve Makarnalık Buğday (Triticum spp.) Çeşitlerinin In vitro Koşullarda Tuza Toleranslarının Belirlenmesi. Doktora Tezi. Ankara Üniversitesi Fen Bilimleri Enstitüsü (Basılmamış). Ankara

Larcher W., 1995. Physiological Plant Ecology. New York. $506 p$

Munns R. and Termaat A., 1986. Whole-plant responses to salinity. Australian Journal of Plant Physiology, 13(1): 143-160

Pancholi S.R., Bhargava S.C. and Singh. A.K., 2001. Screening of wheat genotypes at different salinity levels for germination percentage. Annals of Agricultural Biological Research, $6(1) ; 53-55$

Patterson J. H., Newbigin E., Tester M., Bacic A. and Roessner U., 2009. Metabolic responses to salt stress of barley (Hordeum vulgare L.) cultivars, Sahara and Clipper which differ in salinity tolerance. Journal of Experimental Botany, 60(14): 4089-4103

Parlak M., 1999. Farklı gelisim asamalarında iki arpa (Hordeum vulgare L.) çeşidinin tuza toleransı. Yüksek Lisans Tezi. Ankara Üniversitesi Fen Bilimleri Enstitüsü (Basılmamış) 39 s., Ankara

Pitman M.G. and Läuchli A., 2002. Global Impact of Salinity and Agricultural Ecosystems. Salinity: Environment-Plants-Molecules Published by Kluwer Academic Publishers. Dordrecht. The Netherlands. $522 \mathrm{p}$

Prazak R., 2001. Salt tolerance of Triticum monococcum L.. T. dicoccum (Schrank) Schubl. T. durum Desf. and T. aestivum L. seedlings. Journal of Applied Genetics. 42(3); 289-292
Saboora A., Kiarostami K., Behroozbayati F. and Hajihashemi S., 2006. Salinity ( $\mathrm{NaCl})$ tolerance of wheat genotypes at germination and early seedling growth. Pakistan Journal of Biological Science, 9(11): 2009-2021

Sadat Noori, S.A. and McNeilly, T., 2000. Assessment of variability in salt tolerance based on seedling growth in Triticum durum Desf. Genetic Resources and Crop Evolution, 47(3): 285-291

Soltani A., Ghorbani M.H., Galeshi S. and Zeinali E., 2004. Salinity effects on germinability and vigor of harvested seeds in wheat. Seed Science and Technology, 32(10): 583-592

Sultana N., Ikeda T. and Kashem M.A., 2000. Amelioration of $\mathrm{NaCl}$ stress by gibberellic acid in wheat seedling. Bulletin of Faculty of Agriculture, Niigata University, 52(2); 71-76

Şenay A., Kaya M.D., Atak M. ve Çiftçi C.Y., 2005. Farklı Tuz Konsantrasyonlarının Baz Ekmeklik Buğday Çeşitlerinin Çimlenme ve Fide Gelişimi Üzerine Etkileri. Tarla Bitkileri Merkez Araştırma Enstitüsü Dergisi. 14(1-2) 50-55

Tuteja N., 2007. Mechanisms of High Salinity Tolerance in Plants. Methods in Enzymology, 428: 419-438

Yıldız M. and Özgen M., 2004. The effect of a submersion pretreatment on in vitro explant growth and shoot regeneration from hypocotyls of flax (Linum usitatissimum). Plant Cell, Tissue and Organ Culture, 77(1): $111-115$

Zhu J.K., 2002. Salt and Drought Stress Signal Transduction in Plants. Annual Review of Plant Biology. 53:247-273 